\title{
PRAZER E SOFRIMENTO NO TRABALHO DO VOLUNTÁRIO EMPRESARIAL
}

\author{
Angela Beatriz Scheffer Garay'
}

\begin{abstract}
Resumo
Os programas de voluntariado corporativo representam uma das opções de ações em responsabilidade social bastante valorizadas pelas empresas, sendo sua existência, inclusive, um fator utilizado em instrumentos de avaliação de responsabilidade social (como, por exemplo, o proposto pelo Instituto Ethos) ou em modelos de balanço social (como o proposto pelo Ibase). Em estudo realizado pela autora, buscou-se identificar como o voluntário empresarial, envolvido num cenário organizacional com uma série de novas demandas, percebe esse tipo de trabalho (quais os significados que essa prática assume), bem como suas implicações. Entre os significados encontrados, destaca-se voluntariado como história de vida e como forma de ser reconhecido pela empresa, entre outros, sendo observados ganhos individuais tanto de ordem afetiva como de ordem profissional. Entretanto, foi também percebida, na própria decisão de voluntariar, a percepção da influência de formas de controle mais sutis sobre os funcionários, a reprodução de padrões tradicionais de relações de poder no exercício da ação voluntária, bem como certo nível de sofrimento no trabalho voluntário.
\end{abstract}

Palavras-chave: Voluntariado. Voluntariado empresarial. Responsabilidade Social Corporativa

\section{INTRODUÇÃO}

Tem-se verificado, nos dias de hoje, uma preocupação crescente com a questão da responsabilidade social e do investimento social das empresas, que tem no trabalho voluntário um forte instrumento de ação. Embora o voluntariado (pessoa física) não seja uma prática recente, tem-se assistido à emergência de uma nova tendência social, o voluntariado pessoa jurídica. São empresas privadas que desen-

'Doutora em Administração de Empresas (PPGA/EA/UFRGS). Professora da Escola de Administração da Universidade Federal do Rio Grande do Sul (EA/UFRGS). Universidade Federal do Rio Grande do Sul. Endereço: Rua Washington Luiz, 855, sala 4I 5, Centro, Porto Alegre, RS, CEP 900 I 0-460. E-mail: absgaray@ea.ufrgs.br. Artigo recebido em: 3 I /03/2006. Aceito em 23/03/2007. Membro do Corpo Editorial Científico responsável pelo processo editorial: Prof. Gilberto de Oliveira Moritz 
volvem programas de voluntariado com o objetivo de estimular seus funcionários a atuarem junto ao campo social.

Como estratégia de intervenção social, muito se tem dito sobre a contribuição via ação do voluntariado e, particularmente, do voluntariado empresarial (PEREZ; JUNQUEIRA, 2002; CORULLÓN; MEDEIROS FILHO, 2002; PARCEIROS VOLUNTÁRIOS, 2001). De modo geral, destacam-se o desenvolvimento social a partir da utilização do potencial humano; a intervenção de maneira conseqüente e permanente na vida social; a capacidade de levar o público interno das empresas a abraçar conceitos como o de responsabilidade social; assim como a própria otimização dos investimentos das empresas na área social, pela aproximação com as comunidades. Como estratégia empresarial, destaca-se a possibilidade de humanização do trabalho, criação de um estímulo visando maior interação com a comunidade, o desenvolvimento de competências dos funcionários ou mesmo o fortalecimento da imagem da empresa junto à comunidade, demandas derivadas das transformações no cenário organizacional dos últimos tempos (GARAY, 2003).

Tem-se que a ação voluntária está ligada, de modo geral, a ação espontânea com base na solidariedade, benevolência, afeto, compreensão e responsabilidade para com os outros, o que neste cenário das organizações pode assumir diferentes interpretações. Dessa forma, buscou-se identificar quais seriam o (s) significado(s) que o trabalho voluntário assume para o profissional que o realiza, com base em estudo de caso realizado em duas grandes empresas gaúchas, nas quais foram entrevistados voluntários empresariais e dirigentes responsáveis por esses programas. Parte de uma discussão teórica sobre os significados usuais associados ao voluntariado e sobre questões envolvendo poder, controle, organização do trabalho e prazer e sofrimento no trabalho. Após, apresenta a metodologia do estudo e seus resultados principais.

\section{O TEMA EM QUESTÃO: UMA BREVE FUNDAMENTAÇÃO TEÓRICA}

\subsection{O sentido do trabalho voluntário para os indivíduos}

Trabalho voluntário tem sido definido como o esforço oferecido espontaneamente, ou a pedido, e sem remuneração por qualquer pessoa que deseje colaborar com amor, benevolência, afeto, compreensão e responsabilidade em organismos que trabalham em favor do bem-estar da comunidade, nascendo de uma vontade própria (KOHAN, 1965).

No Brasil, o termo e a ação voluntária ainda estão muito associados a valores religiosos, caridade e concepções como assistencialismo, trabalho de menor importância e até mesmo demagogia, o que justifica certa desconfiança ou desvalorização em relação àquele que quer dar algo gratuitamente e em relação a sua ação. A própria relação entre 
benfeitor e beneficiário, ao longo da história, adquiriu um caráter assistencialista, em que, muitas vezes, benfeitor e beneficiado pouco conhecem de suas respectivas realidades, do que resultam poucos ganhos da relação (MARTINELLI, 1996).

Drucker (1977) menciona a realização, a satisfação em servir e a possibilidade de uma contribuição clara como os principais elementos que dão sentido ao trabalho voluntário no Terceiro Setor. Além disso, os voluntários vivem na comunidade e exemplificam a missão da instituição (DRUCKER, 1997).

Diferentemente do trabalho sob o controle comumente existente nas organizações com fins lucrativos, Ribeiro et al. (1996) consideram que o trabalho voluntário seria um espaço no qual o investimento narcísico (investimento libidinal do ego) poderia renovar-se, assim como representaria a busca de uma forma de satisfação, em uma tarefa plena de significações, a partir da escolha por uma vida ativa e voltada para o outro, para o mundo.

Alguns estudos quantitativos (PENNER; FINKELSTEIN, 1998; OKUN, BARR; HERZOG, 1998), buscam identificar os fatores que levam as pessoas a voluntariar e os fatores que fazem com que elas continuem voluntariando por longos períodos. Penner e Finkelstein (1998) citam dois modelos mais conhecidos: o modelo do processo voluntário e o modelo da identidade do papel.

O primeiro modelo se preocupa com os antecedentes do voluntariado e com o que acontece com os voluntários ao longo do tempo, apontando para algumas variáveis disposicionais que influenciam na decisão de voluntariar: as experiências de vida, as circunstâncias, os motivos pessoais e as necessidades sociais.

Segundo esse modelo, para entender por que uma pessoa oferece ajuda, é necessário entender que funções particulares o fato de ajudar representa para ele ou ela. $\mathrm{O}$ fato de continuar a voluntariar depende da relação que se estabelece entre o voluntário e a instituição em que ajuda, tendo influência as seguintes variáveis: satisfação com a organização, sentimentos positivos em relação a ser voluntário, comprometimento com a organização e união entre as experiências de voluntariado e a personalidade do indivíduo e suas motivações sociais.

No que tange especificamente à motivação para voluntariar, destaca-se o modelo multifatorial (CLARY; SNYDER; RIDGE, 1992 apud OKUN; BARR; HERZOG, 1998) que identificou seis funções primárias que levam os sujeitos a voluntariar:

a) os valores (crença profunda na importância de ajudar os outros);

b) o aspecto social (estando em conformidade com pessoas significantes);

c) a carreira (percepção de possibilidades de ganhos no mundo do trabalho);

d) a aprendizagem;

e) a estima (valor próprio); e

f) a proteção (fuga de pensamentos negativos). 
Por sua vez, o modelo da identidade do papel discutido por Penner e Finkelstein (1998) dá atenção à teoria do papel e da estrutura social na qual o voluntariado ocorre para explicar essa ação. Esse modelo sinaliza que, na medida em que as pessoas continuam a voluntariar, o comprometimento com a organização aumenta, assim como aumenta a incidência de ações em benefício da organização. Esse processo é acompanhado de mudanças no autoconceito dos voluntários, no qual o papel de voluntário se torna parte de sua própria identidade.

Essas abordagens contribuem para a análise da ação do voluntário empresarial em suas decisões, que partem de motivações pessoais e que ocorrem em um contexto de relação com a empresa. Além disso, no momento em que passam a atuar, passam a existir expectativas da instituição em que o voluntário colabora com sua ação, assim como expectativas do grupo de funcionários que se une para desenvolver uma ação social.

\subsection{A questão do trabalho: breves considerações acerca de poder, controle, organização do trabalho e prazer e sofrimento}

Trabalho representa para os indivíduos não apenas uma forma de ganhar a própria vida, mas sim fonte de identificação própria, frente aos seus grupos de pares e até da sociedade como um todo, constituindo-se em uma forma de inserção social. Essa identidade é construída pelo indivíduo no dia-a-dia de trabalho, a partir das experiências por ele vivenciadas, e o acompanha marcantemente em toda sua vida.

Porém, nem sempre o trabalho pôde ser visto como fonte de prazer, de realização, permitindo a satisfação dos desejos e aspirações dos indivíduos. Durante muito tempo, especialmente a partir da organização do trabalho baseado nas práticas tayloristas/fordistas, que propiciaram a divisão do trabalho, a simplificação dos instrumentos de trabalho, a especialização, a separação entre planejamento e execução, entre outras características que levaram o trabalhador cada vez mais a afastar-se do produto de seu trabalho, a subutilizar suas potencialidades e seu saber, trabalho foi visto como ação quase que desumana. Tal organização do trabalho caracterizou-se por um controle disciplinar, em uma organização rígida, com a fragmentação das atividades, do pensar e do fazer, do espaço e do tempo, com uma padronização dos movimentos e apropriação dos saberes coletivo.

Hoje, a chamada terceira revolução industrial - com base na microeletrônica e na especialização flexível - levou a uma série de mudanças na organização do trabalho que trouxe avanços na perspectiva de humanização das relações de trabalho e de revalorização do trabalho, com a ênfase na qualificação e na cooperação. Entretanto, na opinião de diversos autores (LEITE, 1993; CASTRO, 1993; PAIVA, 1993), essa nova forma de organização do trabalho, com a utilização de novas tecnologias que 
buscam criar ambientes de trabalho mais participativos, cooperativos, menos alienantes e controladores, com um trabalhador mais qualificado, com maior domínio do processo, levou a outras formas de controle, agora mais internalizadas, baseadas na utilização da chamada subjetividade do trabalhador, que traz diferente tipo de sofrimento e desumanização ao trabalho. Segundo Grisci, Hofmeister e Cigerza (2004), há a necessidade de o trabalhador estar aberto para as novas demandas do trabalho (comprometido com sua empregabilidade) e as regras da competitividade, havendo uma produção de todo um estilo de vida a quem a administração outorga uma margem de liberdade em troca de uma maior disponibilidade ao trabalho, mobilidade e criatividade. Ocorre uma passagem do controle para o autocontrole, estabelecendo-se ainda uma maior competitividade nas relações.

Além disso, como aponta Enriquez (2000, p.18), a empresa se instaura como o ator principal da sociedade e exporta para as outras organizações os seus valores (a competição e o sucesso econômico), sua visão pragmática do mundo, suas normas de eficácia, de combate, de performance. Ou seja, exerce uma pressão para instaurar a ordem das coisas (regulação social), demandando uma série de novos comportamentos e posicionamentos frente ao trabalho e as organizações.

É também nesta organização que os medos são manipulados: o medo de perder o emprego, de perder prestígio, de não ter chances na carreira, a vergonha do fracasso, da inadaptação, etc., sendo que o controle do medo é extremamente desgastante, assim como acaba individualizando os trabalhadores. Henriquez (2000) refere que a organização, por ele chamada de estratégica, exige que o indivíduo a idealize, identifique-se com ela, mas também quer sua devoção incondicional, exigindo o desempenho de um herói criativo, um guerreiro, um ganhador. Ao mesmo tempo, tanto o sucesso como o fracasso não são imputados à estrutura da organização, mas a atitude do indivíduo que deve superar todas as provas que tem que enfrentar, reforçando o sentimento de culpabilidade (ideal do homem do homem passa a ser confundido com o ideal da organização), o que também é capaz de gerar sofrimento no trabalho.

Como colocam Batista e Codo (2002), o mundo do trabalho tornou-se, em poucas décadas, o espaço da insegurança, da incerteza, da negociação permanente das condições de continuidade do emprego, bem como a exigência de autonomia, criatividade, versatilidade, junto com a exigência de trabalhar em grupo interpelam, em parte, no indivíduo, sua capacidade de ser "eu" tanto quanto a de ser "nós". Além disso, a flexibilidade tão desejada nesse novo contexto acabou levando a que as relações entre trabalhadores e organizações se tornassem mais utilitárias, se volatizando a trajetória profissional.

Há ainda as pressões exercidas pelos clientes, a introjeção da dominação (passam a exigir de si mesmo o máximo de produtividade), as leis de mercado tão difundidas. 
A organização utiliza-se, então, de diferentes estratégias que possibilitam o aumento da produtividade bem como do controle. As organizações, como coloca Pagès (1987), na determinação da forma e do conteúdo das regras e os princípios que regem as relações no seu interior, procuram apresentá-las como necessidade, como ordem das coisas, acima de sua própria vontade, exercendo um poder mediador. Segundo esse autor, a dinâmica do poder reside na evolução dos instrumentos de dominação utilizados para manter a supremacia das organizações sobre os indivíduos. As hipermodernas sofisticam esse controle (pela evolução do conhecimento, desenvolvimento tecnológico, redução da zona de aceitação e posição mais ativa dos indivíduos).

Além disso, a organização é ainda um espaço de relações sociais, onde se criam diferentes interesses e identidades coletivas, estabelecendo-se grupos sociais, desigualdades, diferentes acessos aos saberes e hierarquias de poder. Numa compreensão mais ampla, esse espaço, como refere Bourdieu (1996), pode ser visto como um campo de forças e de lutas construído pela ação de agentes que se enfrentam, com meios e fins diferenciados, conforme suas posições relativas em espaços de relações. As lutas inerentes aos campos sociais, e a conseqüente mobilização dos tipos de capital (de poder), ocorrem pela existência de interesses em jogo. Ter interesse é "estar em", é participar, é admitir que o jogo merece ser jogado e que os alvos envolvidos merecem ser perseguidos.

Ainda conforme Bourdieu (1996) é nesse espaço social que ocorre uma distribuição de formas de poder (tipos de capital) que variam conforme o universo social considerado. Esses campos exigem daqueles que nele estão envolvidos um saber prático das leis de seu funcionamento, isto é, um habitus adquirido pela socialização prévia e/ou por aquela que é praticada no próprio campo, bem como são constituídos de um sistema padronizado de forças objetivas. Há agentes que lutam, dependendo de posições que ocupam no campo, ou para mudar ou para preservar seus limites e forma, sendo os próprios limites do campo um objeto de disputa.

Desta forma, o trabalho se torna tão complexo na sua significação para o indivíduo, podendo ser ao mesmo tempo fonte de prazer e de sofrimento. Segundo Dejours (2001), o trabalho é uma fonte inesgotável de paradoxos, pois tanto pode ser uma atividade física como intelectual, um ato compulsório ou de criação, um meio de subsistência ao mesmo tempo em que pode proporcionar auto-realização, status e identidade. Trabalho pode causar infelicidade, alienação e doença mental, mas também pode ser instrumento a serviço da emancipação, bem como do aprendizado e da experimentação, da solidariedade e da democracia, ser mediador da auto-realização, da sublimação e da saúde.

Assim, é a partir desse cenário que a presente pesquisa busca verificar como o trabalho voluntário passa a ser percebido e quais suas implicações para esses sujeitos. Este artigo analisa em especial a questão do prazer e do sofrimento envolvido no trabalho do voluntário empresarial, a partir da compreensão das vivências subjetivas desses sujeitos em sua situação de trabalho. 


\section{METODOLOGIA}

Para este estudo, foram conduzidos estudos de caso em duas grandes empresas gaúchas que contam, dentre outras ações sociais, com programas de voluntariado. Três critérios foram utilizados como base para a escolha dessas empresas: que elas (a) tivessem programa em andamento; (b) que tivessem sua ação junto a instituições do campo social ou projetos sociais que visassem ao público externo e (c) que as ações não fossem apenas pontuais. A opção recaiu pelo estudo qualitativo na medida em que os objetivos do estudo implicam em uma metodologia que possibilite a interpretação dos fenômenos. A opção pelo estudo de caso deu-se em função, como refere Yin (1994), destes serem estratégias de pesquisa preferidas quando questões do tipo "como" ou "porque" são requeridas, quando o investigador tem pequeno ou nenhum controle sobre os eventos, ou ainda quando o foco é buscar entender um complexo fenômeno contemporâneo dentro de um contexto.

A escolha deu-se a partir da consulta disponível em revistas e artigos sobre empresas que realizavam programas de voluntariado e, principalmente, pela indicação de pessoas com vivência no campo social. Foram entrevistados seis profissionais (sondagem de opiniões), dentre consultores e jornalistas atuantes junto ao Terceiro Setor, que sinalizaram um conjunto bastante pequeno de empresas.

A partir de entrevistas em profundidade realizadas com voluntários (aleatoriamente convidados) participantes do programa das organizações escolhidas, buscou-se examinar qual(is) seria(m) o(s) significado(s) que este profissional imprime à ação voluntária quando esta é estimulada a partir de um programa da empresa, bem como os ganhos que obtém.

Para a análise do fenômeno em questão, utilizou-se análise de conteúdo, conforme definido por Bardin (1991), método que busca sistematizar e explorar os dados (no caso as percepções levantadas nas entrevistas) que são de natureza qualitativa. A análise de conteúdo representa "um conjunto de técnicas de análise de comunicações visando obter, por procedimentos sistemáticos e objetivos do conteúdo das mensagens, indicadores que permitam a inferência de conhecimentos relativos às condições de produção/recepção destas mensagens" (BARDIN, 1991, p.42). Como refere Moraes (1999), é uma metodologia de pesquisa usada para descrever e interpretar toda a classe de documentos e textos, permitindo a reinterpretação das mensagens de modo a atingir uma compreensão de seus significados que vai além de uma leitura comum. Todas as entrevistas foram gravadas e transcritas, a partir do qual se organizou as informações coletadas em categorias iniciais de análise, que após foram condensadas em categorias intermediárias e categorias finais, representativas, no caso, dos significados atribuídos à ação voluntária. 


\section{APRESENTAÇÃO DOS RESULTADOS PRINCIPAIS DO ESTUDO}

\subsection{Descrição dos casos}

As empresas em estudo são indústrias de grande porte. Um comparativo é traçado no quadro 1 , sendo a sigla PV equivalente a programa de voluntariado.

\begin{tabular}{|c|c|c|}
\hline Características & Empresa 1 & Empresa 2 \\
\hline $\mathrm{N}^{\circ}$ de funcionários & $\begin{array}{l}4.500 \text { no Brasil } \\
450 \text { na unidade em questão }\end{array}$ & 668 na empresa 2 \\
\hline $\begin{array}{l}\mathrm{N}^{\circ} \text { de voluntários } \\
\text { participantes no PV }\end{array}$ & 25 funcionários & 10 funcionários \\
\hline Responsável pelo PV & $\begin{array}{l}\text { Próprios funcionários, em programa } \\
\text { acompanhado pelo instituto } \\
\text { empresarial }\end{array}$ & Área de Recursos Humanos \\
\hline Entrevistas realizadas & 10 entrevistas no local de trabalho & 8 entrevistas no local de trabalho \\
\hline Análise de documentos & $\begin{array}{l}\text { Jornais internos, documentos } \\
\text { internos da empresa, publicações em } \\
\text { jornais e revistas }\end{array}$ & $\begin{array}{l}\text { Jornais internos, documentos } \\
\text { internos da empresa, publicações } \\
\text { em jornais e revistas }\end{array}$ \\
\hline
\end{tabular}

Quadro 1 - Casos estudados e aspectos metodológicos

Fonte: dados de pesquisa

Na empresa 1, cerca de 5,5\% dos funcionários voluntariam no projeto incentivado pela empresa (de 450 empregados na unidade da empresa foco do estudo, 25 têm seus nomes relacionados no projeto). Na empresa 2, o percentual cai para $1,5 \%$ dos empregados (dos 668 empregados, 10 voluntariam no programa em análise).

No caso 1, a idéia do programa de voluntariado foi desenvolvida pelo instituto empresarial a ela vinculado, como forma de comemorar seu primeiro ano de atividade e o Ano Internacional do Voluntariado, além da busca por alavancar o voluntariado interno da mantenedora (meta). Partiu de um convite aos funcionários de todas as unidades no Brasil para que elaborassem projetos sociais e os encaminhassem para um processo seletivo.

Inicialmente, foi enviada uma circular a todas as unidades da empresa no Brasil e, nominalmente, foi entregue um convite para o endereço residencial de cada um dos 4.500 funcionários. Esse convite continha uma carta de apresentação e informações sobre o processo seletivo. A carta finalizava com "Contamos com todos vocês" ou ainda "Esta é sua chance de contribuir para a execução de projetos sociais bemsucedidos, exercendo o seu papel de agente de desenvolvimento humano". 
Os funcionários deveriam ainda preencher dados referentes a uma instituição sem fins lucrativos que receberia a ajuda dos voluntários, com detalhes das ações e das propostas. Posteriormente, o mesmo convite foi colocado na intranet da empresa, para que os funcionários pudessem acessar eletronicamente os formulários de inscrição. Além disso, foram colocadas notícias em pelo menos quatro boletins de circulação interna do Instituto.

O apoio principal dado pelo Instituto seria o aporte financeiro, que duraria um ano. Houve orientações e esclarecimentos quanto à elaboração dos projetos e os eleitos receberam acompanhamento durante o ano. A previsão de continuidade do projeto, após os 12 meses desse auxílio financeiro, deveria ser contemplada nos projetos desenvolvidos. Não estava previsto o uso de horas de trabalho para a realização do projeto. Conforme relato de um dos entrevistados (um dos organizadores/incentivadores do programa): "A gente faz questão de que voluntariado seja uma coisa bem pessoal, seja fruto de um investimento individual, como contribuição para o desenvolvimento social".

$\mathrm{O}$ projeto selecionado da unidade em estudo refere-se à ajuda a uma instituição carente da região que atende idosos. Iniciou-se com um grupo de funcionários da fábrica (três gerentes) que, face ao apelo do instituto, tomou iniciativa e foi conhecer algumas instituições da região. Após conhecerem quatro instituições, chegaram a uma determinada instituição, carente, que não recebia ajuda de nenhum órgão municipal ou estadual.

O projeto foi divido em três etapas: uma que seria civil, uma de treinamento e outra, assistencial, cada parte ficando sob a responsabilidade de um dos gerentes. $\mathrm{O}$ valor total do projeto era de $\mathrm{R} \$ 103.000,00$, incluindo a contratação de estagiários e de algum funcionário (psicóloga ou assistente social que pudesse dar apoio e acompanhar o andamento do projeto). O grupo julgou que seria mais interessante, ao contrário do que ocorreu nos outros projetos selecionados, que o Instituto não simplesmente transferisse o dinheiro para a instituição. "Nós queríamos que o dinheiro ficasse na mão do Instituto e nós iríamos administrar esse dinheiro para fazê-lo render um pouco mais" (relato de um dos voluntários).

Aos poucos, o grupo começou a fazer reuniões com outros funcionários, até que vinte e cinco (25) profissionais se engajaram no processo, entre engenheiros, médicos, enfermeiros, gerentes e outros. Prevendo a continuidade do projeto (para além dos 12 meses), a universidade local foi eleita como parceira fundamental. Foi contratada uma profissional ligada à área da saúde para "servir de ponte", conforme referido por um dos entrevistados, entre o grupo de voluntários e a instituição social.

No caso 2, o programa de voluntariado é considerado uma evolução de outro já existente, criado em 1993 por uma fundação empresarial, antes de a empresa ser adquirida por um grupo estrangeiro. A idéia de ter um programa de voluntariado surgiu na área de Recursos Humanos com o objetivo de, especialmente a partir do uso das competências dos funcionários em gestão e da transferência de cultura or- 
ganizacional do setor empresarial para as organizações da sociedade civil, auxiliar no desenvolvimento de programas geradores de renda que assegurassem a autosustentabilidade da entidade beneficiada, o que, porém, exigia processos mais longos e de resultados mais demorados.

O programa anterior, tal como criado, funcionou durante algum tempo na empresa 2. Em seu formato atual, segundo relato do entrevistado (responsável pelo programa), passou a existir a partir de 1997. As mudanças que ocorreram se deram especialmente no que diz respeito a uma desburocratização do processo. Hoje priorizam-se as campanhas. Participam dez pessoas de diferentes setores, sendo este o número mínimo de funcionários para que possa funcionar.

\subsection{Os significados atribuídos ao trabalho voluntário}

A partir da análise de conteúdo realizada, foi possível a identificação de alguns significados atribuídos à ação voluntária. $\mathrm{O}$ quadro 2 - Comparativo com base na análise de conteúdo - coloca em evidência as categorias intermediárias e finais que emergiram a partir dessa técnica.

\begin{tabular}{|c|c|c|}
\hline & Empresa 1 & Empresa 2 \\
\hline \multirow{3}{*}{$\begin{array}{l}\text { Categorias } \\
\text { finais }\end{array}$} & $\begin{array}{l}\text { O prazer na ação voluntária: a lógica } \\
\text { substantiva na visão de ser voluntário }\end{array}$ & $\begin{array}{l}\text { O prazer na ação voluntária: a lógica } \\
\text { substantiva na visão de ser voluntário }\end{array}$ \\
\hline & $\begin{array}{l}\text { Trabalho voluntário como uma relação } \\
\text { de troca com a empresa: a lógica } \\
\text { instrumental em ação }\end{array}$ & $\begin{array}{l}\text { Trabalho voluntário como uma } \\
\text { relação de troca com a empresa: a } \\
\text { lógica instrumental em ação }\end{array}$ \\
\hline & $\begin{array}{l}\text { Voluntariado como ação social da } \\
\text { empresa: um novo e desconhecido campo } \\
\text { mediado pela imagem }\end{array}$ & $\begin{array}{l}\text { Voluntariado como ação social da } \\
\text { empresa: um novo e desconhecido } \\
\text { campo mediado pela imagem }\end{array}$ \\
\hline \multirow{8}{*}{$\begin{array}{l}\text { Categorias } \\
\text { intermediárias }\end{array}$} & Voluntariado como história de vida & Voluntariado como história de vida \\
\hline & Ação movida pela emoção & Ação movida pela emoção \\
\hline & $\begin{array}{l}\text { Visões do papel gerencial face ao } \\
\text { programa de voluntariado }\end{array}$ & $\begin{array}{l}\text { Trabalho voluntário como uma } \\
\text { demanda organizacional }\end{array}$ \\
\hline & $\begin{array}{l}\text { O orgulho pela empresa e por seus } \\
\text { valores }\end{array}$ & $\begin{array}{l}\text { Voluntariado na empresa: desencanto } \\
\text { com seu valor }\end{array}$ \\
\hline & \begin{tabular}{|l|} 
Trabalho voluntário: a racionalidade em jogo \\
\end{tabular} & A empresa que busca ganhos \\
\hline & $\begin{array}{l}\text { A preocupação com uma imagem a ser } \\
\text { passada }\end{array}$ & $\begin{array}{l}\text { A preocupação com uma imagem a } \\
\text { ser passada }\end{array}$ \\
\hline & $\begin{array}{l}\text { Trabalho voluntário: os temores face às } \\
\text { novas relações em construção }\end{array}$ & $\begin{array}{l}\text { Trabalho voluntário: temores face às } \\
\text { novas relações em construção }\end{array}$ \\
\hline & Ação voluntária: pouca transformação & Ação voluntária: pouca transformação \\
\hline
\end{tabular}

Quadro 2 - Comparativo com base na Análise de Conteúdo

Fonte: dados de pesquisa 


\subsubsection{A categoria final "O prazer na ação voluntária"}

A categoria final "O prazer na ação voluntária" foi gerada a partir das categorias "Voluntariado como história de vida" e "A emoção/prazer na ação voluntária" comum as duas empresas. Sinalizam para que o trabalho voluntário, para alguns entrevistados, é movido pela emoção, a partir de uma vontade pessoal, sendo visto como um trabalho com maiores significações. Reforça a noção de que voluntariar se constitui em um processo que, depois de descoberta a satisfação gerada, tende a crescer, acabando por tornar-se parte da própria identidade dos indivíduos, constituindo-se em um valor. Nestes entrevistados, percebeu-se uma relação com suas histórias de vida, sendo um valor compartilhado com pessoas e/ou grupos significantes de suas vidas, como exemplifica os depoimentos: "Quer dizer, quando a gente quer fazer, dá para fazer. Eu queria trazer isso aqui para dentro de alguma forma, e eu nunca consegui porque as pessoas sempre se dizem muito ocupadas, e quando pintou essa chance, é agora ou nunca, e está dando certo .... aprendi com meu pai, eu gostava do que ele fazia, ajudava os outros, mas ele fazia sozinho e hoje a empresal me deu toda essa chance". Ou, na empresa 2: "Começou em Novo Hamburgo. Minha comadre começou a pedir umas vaquinhas para levantar leite pras crianças. Ai eu comecei a levantar leite. Levava 3 ou 4 caixas. E comecei a ir nas festas, eu não tinha filhos. Aí comecei ver a tristeza. Talvez minha ida lá, um sorriso, jogar uma bolinha com as crianças 15 minutos, era uma alegria imensa pra eles, mas pra mim eu vinha muito mais motivado como pessoa e eu queria sair daquele patamar, que eu sempre falo, da demagogia de falar e não fazer. Eu sou mais de fazer, se tem que fazer vamos fazer, se tem que pintar vamos pintar, vamos ter que fazer sinaleira, dai eu comecei a trabalhar com isso com minha comadre de casamento. Ela que me deu uma mão, ela que me empurrou".

Os ganhos de ordem mais afetiva foram os mais valorizados por este grupo, como receber reconhecimento pela ação voluntária, oportunização do exercício de um valor pessoal/familiar e pela a possibilidade de ver a vida com mais alegria, tal como destacado anteriormente na literatura sobre o tema. Destaca-se a fala de um dos entrevistados na empresa 2: "trabalho voluntário é trabalho feito no anonimato", representando uma postura de vida.

Entretanto, destaca-se que esses não foram os únicos sentimentos envolvidos nessa ação.

\subsubsection{A categoria final "Trabalho voluntário como uma relação de troca com a empresa: a lógica instrumental em ação"}

A categoria final "Trabalho voluntário como uma relação de troca com a empresa: a lógica instrumental em ação”, também comum às duas empresas, foi criada 
a partir das categorias "Trabalho voluntário: a racionalidade em jogo", "Visões do papel gerencial face ao programa de voluntariado", "O orgulho pela empresa e por seus valores", na empresa 1, e "Trabalho voluntário como uma demanda organizacional", "Voluntariado na empresa: desencanto com seu valor" e "A empresa que busca ganhos" na empresa 2. Reforça uma lógica instrumental valorativa própria do modo de produção capitalista, orientada para o ajuste do homem à máquina, que confere ao trabalho assalariado uma conotação de dever, de mero fator de produção. Em tal lógica há o predomínio dos critérios técnicos de decisão racional, com finalidade utilitarista atendendo a um determinado fim.

As duas primeiras categorias da empresa 1 trouxeram a percepção dos entrevistados de que, no momento em que se está inserido em uma empresa privada, a decisão de voluntariar torna-se também uma decisão racional, revelando a existência de interesses em jogo nessa relação. O próprio concurso de projetos promovido pelo Instituto empresarial vinculado a empresa 1 foi tomado como um desafio empresarial, algo quase como um negócio, uma competição a ser vencida. Nessa decisão, estariam sendo levados em consideração elementos como o atendimento às expectativas da empresa, propagada por um discurso corporativo de participação na responsabilidade social da empresa. O depoimento de um dos entrevistados ilustra: "Quando vimos a chamada na intranet, queríamos ganhar o projeto, trazer esse dinheiro do instituto para cá. Eu sabia que íamos ganhar. O pessoal tinha dúvida pela escolha do asilo, já que havia a orientação do instituto de priorizar crianças e jovens, eu não, a opção pelos idosos surpreende, o trabalho que fizemos foi bem elaborado. Até porque era interessante para o Instituto ter um projeto aprovado aqui, não tenha dúvida, é uma fábrica importante para eles. Por isso te digo, não se iluda, nada é por acaso, por ser bonzinho. Somos seres racionais, é a razão que conta. As pessoas floreiam demais as coisas".

Surge também a visão da existência de uma expectativa de papel a ser desempenhado, na busca de um maior envolvimento dos funcionários no programa de voluntariado, o que passa, no mínimo, pela sensibilização dos funcionários para essa necessidade e pela ajuda em gestão. "Eu acho que o papel gerencial nosso é tentar motivar os outros para que possam fazer alguma coisas, que as pessoas consigam fazer, tentar mexer com o pessoal, por que não adianta nada ter um projeto, que ta na mão de poucos, dizer que é uma unidade que faz e na verdade são poucos. Essa parte de motivação é de nossa incumbência, cabe a nós incentivar". Esse papel se estende ao auxílio em gestão: "Então a gente acha melhor o seguinte, deixa o seu J. ir administrando, a gente vai acabar, não tenha dúvida, influenciando na gestão dele e já estamos com o projeto em si, mas muito mais através de sugestões, do tipo olha seu J. isso é interessante fazer dessa forma, o que o senhor acha, e ai sim tentar convencê-lo a adotar as idéias que nós demos. 
Porque é isso que a gente já faz no dia a dia com todo mundo aqui, nós somos gestores de negócios e gestores de pessoas e, de repente lá, com certeza a gente vai... isso é meio que inato nosso e está na formação já"

A categoria "Trabalho voluntário: a racionalidade em jogo" discute a racionalidade envolvida na decisão de voluntariar. Trabalho voluntário aparece ligado à idéia de que, a partir de um incentivo da empresa, as pessoas não são mais voluntárias; de que existem influências internas para o voluntariar; de que há todo um jogo de interesses envolvendo o projeto; e de que há o investimento da empresa movido por razões econômicas. "As pessoas não são voluntárias, não se iluda [...] Quando o funcionário faz determinada leitura que está sendo utilizado pela a empresa para atingir determinados objetivos, eles também dizem assim e o meu?" e "Na realidade apareceu dentro da intranet nossa essa proposta do instituto, que ela estava esperando que alguns funcionários fizessem, apresentassem um projeto para alguma instituição na cidade, na região, para que pudessem apresentar projeto e colocar a apreciação do instituto", bem como "No momento em que as empresas passarem a não ter um ambiente em que elas possam ver o seu negócio sustentável, que elas possam, vamos dizer, ter que pensar na continuidade do negócio, tanto da empresa como da convivência de seus funcionários, quando isso vem à tona as empresas passam a se mexer... Para mim essa é a maior motivação, tá, e investem todo o dinheiro possível também para que possam abater do imposto de renda depois, não tenha dúvida, essa é a minha opinião" são falas dos entrevistados que demonstram esses aspectos.

Inclusive os voluntários assumem que o voluntariado é da empresa, usando o tempo de trabalho, ao contrário do que foi proposto pelo instituto empresarial: a expectativa era a de que o voluntariado fosse uma ação bem pessoal, fruto de um investimento individual (voluntariado do funcionário), não estando previsto o uso de horas de trabalho para a realização do projeto.

Além disso, os entrevistados apontaram para um interesse maior da empresa com ganhos de imagem junto à comunidade. Entretanto, sentem a importância em apoiar essa ação social promovida, percebendo que a empresa lhes dá recursos e poder (aos voluntários) e investe em reconhecimento. A preocupação com os outros e a criação de uma relação de confiança são passadas como valores da empresa, o que lhes dá maior conforto. Valorizam, ainda, o retorno dado pela comunidade, o que é fonte de orgulho, bem como a verificação de que essa imagem é resultado de um amplo investimento em projetos sociais que não vêm apenas do "boom" dos últimos anos. Os projetos nunca foram deixados de lado, independentemente do momento por que a empresa passava.

Assim, foram percebidos ganhos mais de ordem profissional, especialmente da empresa 1, em que o grupo assume os papéis que percebem desejados, desempenhando-os da melhor forma possível, o que gera prazer no trabalho e reconhecimento 
tanto dos funcionários da empresa (da fábrica em questão bem como de outras do grupo e do instituto empresarial) assim como da comunidade em que estão inseridos. Sentem e exercem um determinado poder em relação ao instituto empresarial, pois percebem que tanto a empresa como o instituto tem interesses no desenvolvimento desse programa de voluntariado. Pressionam o Instituto para "tomar conta dos recursos", conforme colocação de um dos entrevistados.

Difere do caso da empresa 2, que tem como categoria intermediária "Trabalho voluntário como uma demanda organizacional", que aponta para a percepção da existência de uma expectativa da empresa, percebida especialmente pelo convite, feito pela gerência de projetos sociais a alguns funcionários, de que houvesse engajamento no programa de voluntariado que acabou mobilizando maior parte dos funcionários dessa empresa. O depoimento ilustra: "Então o X me convidou. Tu podes? Eu disse olha, eu posso, mas vou ser bem sincera, com certeza não vou poder me reunir. Ah, mas tem tu tens que fazer uma força. Eu disse que concordo, tudo, não digo que as pessoas estejam erradas, tem que haver tua boa ação pro programa social, mas eu digo assim, olha, infelizmente às vezes nem minha doação vou poder fazer. Tem pessoas maravilhosas, uma delas é o X, o X puxa muito a gente. Então acabei dizendo, eu vou, sempre que possível eu estou a disposição".

Como seria possível dizer não a uma ação nobre, ainda mais partindo de um convite da empresa. No fundo, aparece o medo de perder o emprego, como colocado por um dos entrevistados "se a gente não faz o nosso trabalho, vem alguém e faz". Há a percepção pelos entrevistados de que existe uma certa pressão nos convites efetuados para ingresso no programa de voluntariado, bem como a manifestação de um controle mais internalizado, onde os funcionários percebem que o contexto competitivo faz com que tenham que se adaptar a todo um conjunto de novas demandas traçadas pela empresa.

Pode-se pensar que a diferença encontrada nos dois casos (empresa 1 e 2) aconteceu em decorrência da posição que os entrevistados ocupam na empresa, ou seja, no caso 1 o grupo maior era de gerentes, enquanto no caso 2 era de pessoas em função de assessoria (qualidade, RH), e funcionários administrativos (não gerentes).

Ainda no caso 2, "Voluntariado na empresa: desencanto com seu valor" e "A empresa que busca ganhos" ressaltam a pouca valorização percebida em torno do Programa de Voluntariado, especialmente pelos dirigentes da empresa, que não dão o apoio necessário ao programa, considerado como "superficial". Traz ainda a percepção de alguns de que a empresa se interessa apenas por ter muito a ganhar nesse processo, tanto interna como externamente, não se constituindo, dessa forma, em um valor da organização. "O que, de repente, tá faltando é que o Comitê tá muito parado, já fez muita coisa, mas hoje tá muito parado, precisaria mais de apoio da direção, a direção tem que querer isso. É claro que nós temos a nossa parcela de culpa porque 
não estamos fazendo acontecer isso. A administração precisaria dar o apoio, especialmente que a gente tivesse mais um tempo e recursos disponibilizado pela empresa" e o depoimento "Eu vejo pelo seguinte, porque antes de você saber das necessidades da sociedade que envolve a empresa, nós somos funcionários aqui dentro e vemos funcionários bem, assim, carentes, que precisam de auxílio, no dia a dia do serviço dele ele também tem a comunidade que pertence, os vizinhos", ilustram.

A menor atenção despendida pelos dirigentes aos projetos sociais gerou, de certa forma, frustração no grupo. Percebem os interesses da empresa em relação ao projeto, entretanto, não percebem equilíbrio entre o nível de demanda e os recursos ou benefícios oferecidos. A direção faz convite, mostra seu interesse, mas pouco dá de retorno - não apóia, não dá recursos, mostrando-se mais preocupada em mostrar publicamente os ganhos que são da empresa (prêmios recebidos).

Nota-se, a partir do que foi exposto, que existe uma certa dose de sofrimento na ação desses voluntários, fruto de percepções de pressões, demandas sem contrapartidas e expectativas de parte da empresa, que faz com que muito da energia livre disponível (como a energia criativa) de cada um seja deslocada para funções menos saudáveis. Ou seja, pode-se pensar que, como muitos dos entrevistados não se identificam com o voluntariado, seja com esse tipo de trabalho ou com o programa em si, não encontrando motivação ou satisfação nesta atividade, não conseguem também se libertar desta atividade (por perceberem o desejo da empresa, por perceberem a valorização dessa atividade pelas organizações em geral, e até por temerem a perda de seus empregos, entre outros medos). Especialmente no caso da empresa 2, muitos dos voluntários não têm demonstrado vontade de realizar as ações do Comitê, inclusive pouco ou quase nada fazendo, mas também não têm conseguido resolver essa situação, o que acaba tornando-se um incômodo. Precisam ficar se justificando, e aos outros, quanto ao porquê deste quadro, o que gera um incômodo, um conflito interno, sem conseguir se libertar. Precisam se mostrar como perfeitos, participantes, atuantes em conformidade com os desejos da organização, como demonstra de modo mais preciso a categoria final a seguir.

\subsubsection{A categoria final "Voluntariado como ação social da empresa: um novo e desconhecido campo mediado pela imagem"}

"A preocupação com uma imagem a ser passada", "Trabalho voluntário: os temores face às novas relações em construção" e "Ação voluntária: pouca transformação", comum às duas empresas acabaram gerando a categoria final "Voluntariado como ação social da empresa: um novo e desconhecido campo mediado pela imagem".

Sinalizam que, segundo a percepção de alguns entrevistados, muito da ação tem ficado no campo do discurso, sendo ainda pequena a participação ou o envolvimento 
real junto às organizações que recebem a ajuda. Os depoimentos ilustram: "o que aconteceu, o ano retrasado foi um ano que não teve muitas atividades porque estavam muito burocratizadas, engessadas ... atualmente não se tem feito nada. No dia do voluntariado se queria fazer a pintura de um asilo, mas até que se conseguisse a tinta, não sei mais o que, aí começou o período de chuvas, aí não de podia pintar porque era inverno, depois veio o verão ... mas se perdeu. Tem muito a se fazer, mas não se está fazendo nada" (empresa 2) e ainda "Eu fui bem real aqui, viu, reconheço que não estou fazendo nada e que a maioria não está. Muito está acontecendo no papel, eles estão com o nome lá, foram convidados para participar, mas não estão envolvidos, só alguns que eu te falei. Até quando foi para bater a foto do jornalzinho tivemos que sair catando pessoas para aparecerem" (empresa 1).

Entretanto, em todas as entrevistas foi revelada uma preocupação com uma imagem interna e externa a ser passada, imagem interna do profissional que adere às novas demandas da empresa (que o faz mediante uso do gerenciamento da impressão). O uso do gerenciamento da impressão foi percebido nas falas dos entrevistados, que pareciam estar mais preocupados com uma imagem a ser passada do que mostrar as dificuldades em sua participação e envolvimento real no projeto, representando uma estratégia para afetar impressões (criando-se uma imagem social desejada) em "uma teia de relações, onde afetar as impressões dos outros atores sociais sobre si mesmo faz parte do jogo" (MENDONÇA; GONÇALVES, 2002, p.2). Nesse sentido, voluntariado é percebido como forma de ser reconhecido pela empresa ("faço parte").

$\mathrm{Na}$ empresa 1 precisam mostrar a imagem de que são perfeitos, que se enquadram nas demandas atuais da empresa. Seus discursos procuram passar uma imagem positiva da empresa e deles, como profissionais. Os funcionários, assim, protegem-se contra sentimentos/angústias, assim como procuram proteger a imagem da empresa e sua própria imagem. Procuram, neste sentido, mostrar que compartilham do desejo da empresa, estando sempre dispostos a assumir novos desafios, nem que seja apenas no discurso.

A organização faz uso do poder simbólico, mostrando-se como aquela que tem um projeto nobre, que se preocupa além dos ganhos econômicos, que busca internamente o desenvolvimento de uma relação de igual para igual, num espaço democrático, que ultrapassa fronteiras, inclusive além da empresa.

Quanto à imagem externa, os entrevistados percebem haver um interesse da empresa, a partir de suas ações sociais, na busca de credibilidade junto à comunidade, melhorando as atitudes em relação a suas ações, além de buscar inspirar o desejo de trabalhar para ela e conseguir a aprovação de leis que a favoreçam, entre outras vantagens.

Em termos da pouca transformação percebida, ocorre que a ação realizada em ambas as empresas tem sido de caráter mais assistencialista, não havendo a 
busca por uma interação maior junto às organizações sociais que possa gerar um crescimento para os indivíduos. O depoimento "A gente vem trabalhando só em ações pontuais, que também são válidas, junta roupas, alimentos, enfim, mas não há continuidade" exemplifica.

Assim, quanto à questão da interação com a sociedade, em ambos os casos, a ação realizada pelos voluntários junto às instituições sociais está ainda longe de uma transformação social, capaz de desencadear a participação social dos envolvidos desenvolvendo a cidadania dos agentes envolvidos. Percebeu-se um distanciamento em relação ao outro, sejam os idosos, sejam as crianças, sejam os portadores de alguma deficiência. A solidariedade apareceu como ajuda material, importante, sem dúvida, porém colocando, de um lado, os agentes sensibilizados com as necessidades sociais, e, de outro, os agentes atingidos pelas vicissitudes das mesmas, formandose uma relação de superioridade diante da dívida que se estabelece diante do que recebe, passível de se transformar numa relação de dependência. Além disso, não foi percebida alguma preocupação com as diferenças nos pressupostos e nas abordagens adotadas nos dois campos, o do privado e do campo social.

Verificou-se nessa ação a reprodução de relações mais autoritárias e de dependência na medida em que não há a busca por um processo de aprendizagem com base no desenvolvimento da cidadania. Caberia à instituição beneficiária da ação voluntária se adaptar à lógica empresarial, podendo utilizar-se do conhecimento e da experiência em gestão propiciada pelos voluntários e das ferramentas disponíveis no universo das empresas privadas.

O grupo de gestores, especialmente na empresa 1, representa a autoridade legítima que tem no seu conhecimento (vindo do acesso às instituições de ensino e de sua prática profissional) um recurso diferenciado. $\mathrm{O}$ grupo de funcionários das organizações privadas detém, assim, um importante capital que é posto em jogo, manifestando a construção de uma relação de poder desigual entre diferentes agentes sociais (eles detêm todo um conhecimento e as instituições são pouco profissionais ou não honestas).

Já a categoria intermediária "Trabalho voluntário: os temores face às novas relações em construção", encontrada nas duas empresas, destaca um conjunto de temores envolvendo os atores/instituições que estão presentes, haja vista essa ser uma ação em um campo desconhecido para muitos. Na empresa 1 , surgiram temores quanto à possível associação entre carreira e voluntariado e à falta de profissionalismo existente nas instituições sociais. Na empresa 2, destacaram-se os temores quanto ao uso indevido das ações realizadas (com o uso do trabalho voluntário como forma de gerar ganhos para a empresa) e à falta de informações sobre a idoneidade das instituições.

"O que a gente assiste é que em diversas empresas passaram a ter isso... talvez sei lá como um pré-requisito para encarreiramento, uma possibilidade maior até mesmo para permanecer dentro da empresa por mais tempo" e "O ano passado, 
o ano retrasado, quando eu estava fazendo seleção de trainees, fui desclassificado na Ford por justamente não ter nenhum projeto de voluntariado, e aquilo lá fez minha cabeça. O que é isso, ser desclassificado na hora final, do desempate, por não ter participado de voluntariado" (empresa 1). Na empresa 2: "Eu não procuro associar o voluntariado apesar de já ouvir... sinceramente eu nem gosto desse tipo de coisa, nem gosto que associe esse negócio porque começa a criar pessoas com olhos errados, entende, que tentam se promover em cima de coisas sérias, porra, onde existem necessidades, as pessoas estão querendo ajuda", revelando um temor de que o trabalho voluntário torne-se mais uma tarefa instrumental, voltado principalmente para o desenvolvimento de um negócio, esquecendo-se do processo de ajuda em si ou ainda a noção de que muito da ação está voltada apenas para ganhos de imagem e na busca de receber premiações (que a empresa tem a custo dos que fazem), a empresa tomando-se para si um trabalho que é de alguns.

Em termos da instituição que recebe ajuda, surgiram uma série de receios, muitas vezes frutos de enganos já cometidos. Foram citados o medo da exploração, onde muitos dirigentes das instituições são vistos como acomodados (acostumados a esperar que alguém lhes ajude), o desgosto quando os interesses políticos vêm primeiro e a falta de maiores informações sobre as instituições.

Os resultados provenientes da análise de conteúdo demonstram que não se tem uma ação regida apenas pelos valores, bem como não apenas prazer envolvido nesse tipo de ação voluntária. O prazer aparece de diferentes formas, seja na possibilidade de mudar um contexto, na emoção envolvida, no reconhecimento dado pelos que recebem a ajuda ou mesmo pela comunidade em geral, seja no reconhecimento da empresa ou mesmo em função do poder que lhes é delegado tendo em vista a importância que a ação representa para a empresa. Na empresa 1, pela fala dos entrevistados, a valorização das competências empresariais do grupo representaram motivo de orgulho. O grupo aceitou o desafio, desenvolveu um projeto, foi aceito, quis gerenciar os recursos (conseguiu), sabe negociar, sabe gerir uma fábrica e, por conseqüência, uma instituição, sabe motivar suas equipes, entre outras habilidades apontadas.

Está presente a noção de trabalho voluntário como desejo pessoal, como postura de vida, mas também como fruto de uma decisão racional, face às demandas de uma entidade - a da empresa privada, demandas estas que também geram uma certa dose de sofrimento, seja por exigir mais tempo disponível, envolvimento numa nova área, novas competências, seja pela percepção do uso do voluntariado pela empresa para ganhos próprios, sem real valorização, pelo temor de que voluntariado se transforme em requisito para crescimento na carreira, entre outros aspectos anteriormente salientados, ou mesmo pela energia que precisa ser empregada "justificando" para si mesmo e para os outros a pouca real ação. 
Prazer e sofrimento no trabalho do voluntário empresarial

\section{CONSIDERAÇÕES FINAIS}

Uma das contribuições do estudo foi dar uma visão mais ampla sobre a questão do voluntariado da empresa, ampliando os sentidos que geralmente são dados a essa prática. A imagem de uma ação desprovida de interesses, movida apenas pela vontade de ajudar os outros, pelo sentimento de responsabilidade social, foi somada a existência de outros interesses e de uma ação com outros significados.

Tem-se, então, agentes em um jogo político, estabelecendo relações de poder, buscando ganhos ou mesmo não perdas. Pelo anteriormente descrito, observa-se que os voluntários percebem que fazem parte de um jogo de interesses, aceitam e desempenham um determinado papel, independentemente do voluntariado ser um valor ou não.

Há outro grupo que aceita, mas de forma mais resignada, esforçando-se em passar uma imagem. Percebe que a preocupação maior da empresa é com ganhos de imagem e como isso "joga" de forma mais explícita, fazendo uso intensivo do gerenciamento da impressão. Porém, são esses voluntários que mais sofrem, pois precisam estar constantemente se desculpando ou se justificando para o pouco envolvimento na ação junto às instituições sociais, até porque o programa quando foi criado pressupunha uma participação mais ativa - demonstração de alguma competência especialmente em gestão - num projeto a longo prazo.

Há ainda os que sofrem por terem o voluntariado como um valor e que percebem seu uso pela empresa. Como colocou um dos entrevistados, "um grande problema que eu senti, uma tristeza, porque às vezes tinha aquela coisa - ah, mas nós vamos ganhar tal prêmio -, não fizeram nada pra ganhar tal prêmio (referindo-se ao pouco apoio da empresa e a pouca participação de todos), ai é jogar uma imagem por mercado e tu saber que não é isso, então isso me entristeceu. Outra coisa, entre os nossos meios, todo mundo fala de mim, mas dentro dos meios - Ah, é o fulano e tal", completando que "ter ou não ter (programa de voluntariado) eu faço do mesmo jeito... O ser voluntário ninguém tira, ele trabalha em silêncio, ele é um guerreiro silencioso, vai trabalhando aos poucos".

Especialmente nesta empresa, parecem não ter conseguido dizer não ao convite, até porque sabem que nos dias de hoje é fundamental mostrarem-se dispostos a assumir desafios, comprometidos com a empresa, partilhando de um ideal que é representado pela responsabilidade social da empresa. A empresa usa, de forma mais deliberada, seu poder de empregador, "convidando" os funcionários a fazerem parte do programa de voluntariado, que, mesmo sem se identificarem com a ação, como parece ser o caso de muitos, aceitam essa função.

Não se quer com isso dizer que voluntários empresariais não sejam movidos pela vontade de ajudar o outro. Há os que são movidos por um componente valorativo, especialmente aqueles que já tinham uma história anterior e que tinham pessoas 
importantes ou grupos como exemplos. Neles percebeu-se maior mobilização de um sentimento de ajuda, de afeto na relação com o outro. A cada êxito sentem-se recompensados. Voluntariado aparece com os seguintes significados: voluntariado como um valor pessoal, como história de vida, um tipo de trabalho diferenciado.

Porém, foram encontrados voluntários que organizam e participam de campanhas, mas que nem vão entregar o material recolhido e aproveitar esse momento, sujeitos que desenvolvem ou se integram em um projeto social que pouco vão ou cada vez menos vão às entidades. São sujeitos que se relacionam de uma forma mais distante, ou ainda intermediada, com os beneficiários da ação. Voluntariado aparece como uma ação mediada. Entre o sujeito doador e o beneficiário se coloca um objeto (doação) ou mesmo um sujeito (como a funcionária contratada para servir de elo entre o grupo do projeto e a instituição, no caso da empresa 1).

Encontrou-se também voluntariado como uma demanda organizacional, como desejo da empresa, como uma relação de troca com a empresa (tendo um caráter instrumental), como forma de ser reconhecido pela empresa ("faço parte"), entre outros significados, destacando a percepção de demandas que são institucionais, sociais, psíquicas ou mesmo instrumentais. Lembrando Dejours (1992), entre as tarefas prescritas e a tarefa real existe um espaço de demandas, que pode ser gerador de criação ou de sofrimento, onde os sujeitos metabolizam racionalidades.

Assim, foram encontrados sujeitos que cooperam, embora não apenas por uma adesão emocional (tal como reforçava a literatura), mas também por uma adesão racional em função de uma expectativa de papéis percebida. Afeto e demanda organizacional se alternam. Verificaram-se ganhos pessoais e profissionais importantes para o voluntário empresarial, tal qual relatado nos resultados do estudo, bem como percepções de diferentes interesses e jogos econômicos e políticos na vida organizacional. Percebem o jogo e suas regras.

Retrata-se, desta forma, o ser humano, com toda uma racionalidade e objetividade bem como uma subjetividade que muitas vezes não é devidamente tratada. Muitos estudos acabam por valorizar apenas um desses aspectos, negando conflitos, negando a convivência de diferentes significados, separando aspectos importantes que caracterizam o ser humano e a própria vida organizacional.

Percebeu-se espaço para o prazer, entendido como uma atitude mais alegre em relação à vida e aos companheiros humanos, no qual sentimentos são ampliados (Burrel, 2001), bem como espaço para o sofrimento, seja por parte daqueles que tinham o trabalho voluntário como uma referência maior (como fruto de um valor pessoal ou familiar) ao perceberem os interesses da empresa, seja por parte daqueles sem uma real identificação com o voluntariado que não conseguiram se libertar desta demanda (por perceberem o desejo da empresa), e que precisavam ficar se justificando perante aos outros, revelando nas entrevistas discursos cheios de contradição. 
Além disso, a aproximação entre as pessoas não se estendeu aos mais necessitados (beneficiários da ação), estabelecendo-se uma relação mediada na qual a doação apareceu como preocupação central, bem como o desejo de submeter o outro aos conhecimentos do mundo da empresa privada, manifestando a reprodução de uma relação tradicional de poder. Como coloca Gropp (2002), citando Godelier (1996), o ato de doar institui uma relação dupla de solidariedade, existindo uma relação de superioridade diante da dívida que se estabelece diante do que recebe, passível de se transformar numa relação de dependência. Desta forma, pode simultaneamente "aproximar os protagonistas, posto ser partilha, ao mesmo tempo em que os afasta socialmente pelo fato de estabelecer relações de obrigatoriedade de um retorno" (p.111). Além disso, contém um caráter pessoal, em que a prática da dádiva é relacionada aos que se consideram como superiores (GODELIER, 1996, p.21, apud GROPP, 2002, p.11). Há o sujeito e o sujeitado, que fica com uma dívida de favor pelo bem/serviço recebido, uma gratidão (VIEIRA, 2000).

Assim, finalizando, este artigo buscou um entendimento mais dinâmico acerca dos sujeitos envolvidos na ação voluntária incentivada pela empresa privada, bem como acerca do próprio comportamento organizacional, sinalizando, por exemplo, para a convivência de sentimentos contraditórios (tais como prazer e sofrimento, demanda e ação voluntária) ou mesmo para os jogos de poder existentes.

\title{
SUFFERING AND PLEASURE IN BUSINESS VOLUNTEER' WORK
}

\begin{abstract}
Corporate volunteer programs have been highly regarded by firms as a social responsibility option. Their very existence is a factor considered in social responsibility assesment tools (the Ethos Institute's, for example) or in social balance models (like the Ibase's). In her study, the author attempted to identify how this sort of work and its implications are perceived by enterprise volunteers involved in an organizational environment driven by new demands (which meanings arise from this practice). Among the meanings identified, it stands out volunteering as life experience and as a way to be valued by firms; individual gains both of an affective and professional nature have been observed. However, the decision to volunteer itself revealed the perception of the influence exerted by more subtle control strategies on employees, patterns of traditional power relations reproduced in volunteer actions, as well as some degree of anguish in volunteer work.
\end{abstract}

Keywords: Volunteering. Volunteer program. Corporate Social Responsability. 


\section{REFERÊNCIAS}

BARDIN, Laurence. Análise de conteúdo. Lisboa: Ed.70, 1991.

BATISTA, Analia S.; CODO, Wanderley. O trabalho e o tempo. In: CODO, Wanderley; JACQUES, Maria (Org.). Saúde Mental e Trabalho. Petrópolis: Vozes, 2002.

BOURDIEU, Pierre. Razões práticas: sobre a teoria da ação. Campinas: Papirus, 1996.

BURREL, Gibson. Prazer, sensualidade e diversão nas organizações. In: DAVEL, Eduardo; VERGARA, Sylvia Constant. Gestão com pessoas e subjetividade. São Paulo: Atlas, 2001.

CASTRO, Nadya Araujo. Qualificação, qualidades e classificações. Revista Educação \& Sociedade, n. 45, ago. 1993.

CORULLÓN, Monica; MEDEIROS FILHO, Barnabé. Voluntariado na empresa: gestão eficiente da participação cidadã. São Paulo: Peirópolis, 2002.

DEJOURS, Cristophe. A loucura do trabalho: estudo da psicopatologia do trabalho. 5.ed. São Paulo: Cortez, 1992.

A banalização da injustiça social. 4. ed. Rio de Janeiro: FGV, 2001.

DRUCKER, Peter. Administração de organizações sem fins lucrativos. 4. ed. São Paulo: Pioneira, 1997.

ENRIQUEZ, Eugène. Vida psíquica e organização. In: MOTTA, Fernando; FREITAS, Maria (Org.). Vida psíquica e organização. Rio de Janeiro: Editora FGV, 2000.

GARAY, Angela. Os significados do trabalho do voluntariado empresarial e sua ação junto às Organizações do Terceiro Setor. Tese (Doutorado em Administração), 2003. Escola de Administração/UFRGS, Porto Alegre, 2003.

GRISCI, Carmem; HOFMEISTER, Pedro; CIGERZA, Gilles. Trabalho imaterial, controle e subjetividade na reestruturação produtiva bancária. In: ENCONTRO DA ASSOCIAÇÃO NACIONAL DE PÓS-GRADUAÇÃO E PESQUISA EM ADMINISITRAÇÃ̃, 28, 2004, Curitiba, Anais ..., Curitiba, 2004. 
Prazer e sofrimento no trabalho do voluntário empresarial

GROPP, Beatrice. A ação do voluntário na perspectiva das comunidades de prática enquanto processo de aprendizagem socialmente compartilhado. In: PEREZ, Clotilde; JUNQUEIRA, Luciano (Org). Voluntariado e a gestão das práticas sociais. São Paulo: Futura, 2002.

KOHAN, Felisa F. Entrenamiento para voluntarias en servicio social. Buenos Aires: [s.n.], 1965.

LEITE, Márcia de Paula. Novas formas de gestão da mão-de-obra e sistemas participativos; uma tendência à democratização das relações de trabalho? Revista Educação \& Sociedade, n.45, ago. 1993.

MARTINELLI, Antonio Carlos. Compromisso social da empresa. In: Grandes empresas investindo no desenvolvimento social. São Paulo, AIESEC-FGV, p.5-8, 1996.

MENDONÇA, José R.; GONÇALVES, Júlio C. Responsabilidade social nas empresas: uma questão de imagem ou de substância? In: ENCONTRO DAASSOCIAÇÃO NACIONAL DE PROGRAMAS DE PÓS-GRADUAÇÃO EMADMINISTRAÇÃO, 26, 2002, Salvador:. Anais ... Salvador, 2002.

MORAES, Roque. Análise de conteúdo. Educação, Porto Alegre, ano XXII, n.37, p.7-32, mar. 1999.

OKUN, Morris; BARR, Alicia; HERZOG, Regula. Motivation to volunteer by older adults: a test of competing measurement models. Psycology and aging. v. 13, n. 4, p. 608-621, Dec., 1998.

PAGÈS, Max et al.. O poder das organizações. São Paulo: Atlas, 1987

PAIVA, Vanilda. O novo paradigma de desenvolvimento. In: MACHADO, Lucília et al. Trabalho e educação. São Paulo: Papirus; CEDES, 1992.

PENNER, Louis; FINKELSTEIN, Marcia. Dispositional and structural determinants of volunteerism. Journal of personality and social psycology. v. 74, n. 2, p. 525-537, Feb. 1998.

RIBEIRO, Ana Lúcia ; LIMA, Daniela S.; TAVARES, Raquel P; BERNARDES, Jefferson S. Trabalho voluntário: algumas considerações sobre saúde mental. Psico, v. 27, n.1, p.71-80, 1996. 
VIEIRA, Ana Cristina. Assistencialismo e profissionalização: a trajetória do serviço social. In: FLICKINGER, Hans-Georg. Entre caridade, solidariedade e cidadania. Porto Alegre: EDIPUCRS, 2000.

YIN, Robert K. Case Study Research: design and methods. Thousand Oaks, California: 1994. 